\title{
NEWSPAPER COVERAGE OF DOMESTIC VIOLENCE AGAINST WOMEN IN NIGERIA: A STUDY OF THE SUN, THE GUARDIAN AND THE PUNCH NEWSPAPERS
}

\author{
NKWAM-UWAOMA, ADELINE PhD; OJIAKOR - UMENZE, IFEOMA. C PhD \& \\ NWAMADU, UCHECHI .E \\ Department Of Mass Communication, Imo State University, Owerri
}

https://doi.org/10.37602/IJSSMR.2020.3413

\begin{abstract}
The devastating effect of female domestic violence has been a matter of concern in the world and especially in Nigeria. It is one of the gender-based violence that causes physical, sexual, emotional, mental and economic harm. The need to remedy the rate of domestic violence against women and the girl child cannot be overstressed. The media features as one of the priority area in the prevention of domestic violence. This is because of its potential influence in shaping public opinion. Through news and information, the media can shape public discourse, provide interpretation, build a framework and modify behaviour.

This paper, therefore, investigates newspaper coverage of female domestic violence in Nigeria. Three national newspapers namely the Sun, the Punch, the Guardian were content analyzed for the period of one year (2017). The analysis was based on the frequency, prominence, and depth of their news coverage. A total of seventy-two editions of newspaper were investigated. Frequency table, Simple percentage and charts were used to present the data. The study found that the level of prominence accorded to female domestic violence stories in Nigerian newspapers were low. Though most news stories on the issue received favourable coverage, yet they lack depth and follow up. Intimate partner homicide was the most news story covered by the papers and men were the dominant perpetrates of domestic violence. The authors, therefore, recommend a more representative way of reporting domestic violence against women as this can be part of the solution to eradicate domestic violence in our society.
\end{abstract}

Keywords: Domestic Violence, Newspaper Coverage, Women in Nigeria

\subsection{INTRODUCTION}

Ronke Shonde, a banker and mother of two, was beaten to death by her husband, Lekan Shonde, in Lagos. A manhunt for Mr Shonde, who fled the murder scene, was launched. Before taking his wife's life, Mr Shonde used to "tie her, beat her and take her mobile phones away," according to a neighbour (Usigbe 2018). Media in Nigeria is replete with stories of domestic violence involving women at home or in the streets, many of these with gory 


\section{International Journal of Social Sciences and Management Review}

endings. On December 31, 2017, The Punch newspapers featured a story which indicated that 2017 was a year of deadly domestic violence cases. The publication included stories of tragic occurrence between husbands and wives involving brutal murder. From the publication, it was said that between January and September 2017 a total of 852 domestic violence cases was recorded in Lagos State alone.

On October 11 2017, the report had it that a man killed his wife and afterwards dumped her remains in a rubbish dump. The suspect was said to have used a machete to cut the remains of his wife into pieces which he then gathered into two sacks, put the sack in a wheelbarrow and dispose of them in a rubbish dump. The police said the suspect perpetrated the act in the presence of his three children who later reported the incident to the police. In another report, a man described as a retired boxer was said to have resumed training using his wife as a sparring partner whom he beat to death during Christmas celebration in their home town in Uli Ihiala Anambra State.

Although evidence from the 2013 Nigeria Demographic Health Survey (NDHS) suggests that both men and women are victims of domestic violence, it is overwhelmingly perpetrated by men against women (The Guardian editorial, February 10, 2017). The report also identifies that women and girls are more subject to physical abuse, sexual abuse, psychological abuse and all form of coercion. Perpetrators cut across the line of income, class, race, culture and status.

While domestic violence is a global problem, it has literarily taken residence in Africa with endless stories of pains and sorrow following it. In Nigeria particularly, the epidemic has assumed a disturbing dimension that even current penalties have not been able to serve as a deterrent.

Violence against women as it is sometimes referred to is a manifestation of the unequal power relationship between men and women which has led to domination and discrimination against women by men. (Bakare, Asuquo\&Agomo, 2010). The United Nations defined violence against women as any act of gender-based violence that results in or is likely to result in physical, sexual, or psychological harm or suffering to women, including the threat of such acts, coercion, or arbitrary deprivation of liberty whether occurring in public or in private life (World Health Organization, 1996 as cited in Bakare et al, 2010).

While the concept of physical and sexual violence might be easier to quantify and define across cultures, it might be difficult to define emotional and verbal abuse which women may found more devastating than physical or sexual abuse. Children who grow up in families where there is violence may suffer a range of behavioural and emotional disturbances. These can be associated with perpetrating or experiencing violence later in life. Domestic violence has been associated with higher rates of infant and child mortality and morbidity (for example. diarrheal or malnutrition).

Social and economic effect of Domestic Violence against Women are enormous and can include; women suffering isolation, inability to work, loss of income to the family, lack of participation in regular activities and limited ability to care for themselves and their children. 


\section{International Journal of Social Sciences and Management Review}

In general, violence against women is a major obstacle to human development. It has a huge economic cost and aids the entrenchment of poverty. (Masawa, 2016)

Globally and locally, there have been a lot of organizations and groups who have joined forces to fight for the prevention and eradication of domestic violence especially as it concerns women and children. At the World Health Assembly in May 2016, member States endorsed a global plan of action on strengthening the role of the health system in addressing international violence, in particular against women and girls and against children.

In Nigeria, legal laws such as Violence against Persons' Prohibition (VAPP) Bill which was passed by the Nigerian Senate on 5th May 2015 and signed into law on 24th May 2015 is the only federal-based law targeting gender-based violence and abuse. The law incorporates relevant provisions of international human right laws and principles. Specifically, the law covers such practice as the spousal battery, forceful ejection from home, forced financial dependence or economic abuse, harmful widowhood practices, female circumcision or genital mutilation, harmful traditional practices, substance attacks such as acid baths, political violence and violence by state actors (especially government security forces)

Here comes the responsibility of the media. The media is recognized all over the world as an agent of socialization, which moulds the moral views and opinion of the people. The newspaper and broadcast have been found to reflect and shape public opinion. Newspaper articles have been discovered to have a profound impact on the public perception of Domestic Violence against Women. This is because it is a more permanent form of communication than the broadcast media. Newspaper content is not necessarily absorbed uncritically by readers, therefore the way editors and Journalists frame news stories on Domestic Violence against Women, to a large extent influences the "take-home' massage communicated to readers.

This work is relevant to our society this time in that despite all the echoes on Domestic Violence against Women, the report has shown that Domestic Violence is on the upsurge in the country. It is so commonplace that it is often going on unnoticed. It has also failed to garner the level of concern it deserved (Musawa, 2016).

By way of stating the research problem, a number of studies found that domestic violence on women, which includes sexual and physical forms of violence as well as the homicide of female partners, accounted for a high proportion of the total volume of media reports on violence. It is also discovered that the media lay emphasis more on the method rather than history of the violence as if it is more important for readers to know how but not why. All these seem to make the report on female domestic violence to be overly simplistic, distorted and inadequate which causes lots of public's confusion. Many reports also shift blame to victims and relied on police comments for context. Furthermore in our society, reporting violence seems to be changing the cultural and social norms about gender. In most cases, the newspaper report on violence against women often takes sensational tune with a "pick and drop attitude".

Therefore, this work aims to review the nature of reports on female domestic violence in our national dailies and how newspaper reports on violence against women, can be presented in a 


\section{International Journal of Social Sciences and Management Review}

more accurate way to enhance public understanding and how society sees domestic violence. Specifically, the objectives were to ascertain the frequency of coverage and level of prominence accorded to the coverage of Domestic Violence involving Women by the Nigeria newspaper. Again, the style, depth and direction of newspaper coverage were also accommodated.

Also, this paper hypothesizes that there is a low level of prominence accorded to the coverage of female domestic violence news by Nigerian newspapers.

\subsection{REVIEW OF RELATED LITERATURE}

\section{The Violence Against Persons (Prohibition) Act 2015}

On May 25th 2015, the immediate past President of Nigeria, Dr Goodluck Jonathan recorded a milestone when he signed into law the Violence against Persons Prohibition (VAPP) Act, 2015. This Act, aims to eliminate violence in private and public life, prohibit all forms of violence, including physical, sexual, psychological, domestic, harmful traditional practices; discrimination against persons and to provide maximum protection and effective remedies for victims and punishment of offenders.

This Act commendably covers most of the prevalent forms of violence that could be categorized into: Physical violence; psychological violence; sexual violence; harmful traditional practices; and socio-economic violence.

The following are offences punishable under the Act: Rape, inflicting physical injury on a person, female circumcision or genital mutilation, forceful ejection from home, depriving a person of his/her liberty, forced financial dependence or economic abuse, forced isolation or separation from family and friends, emotional verbal and psychological abuse, harmful widowhood practices, abandonment of spouse, children and another dependent without sustenance, spousal/partner battery, indecent exposure, harmful traditional practices, political violence, and violence by state actors. Other innovations in this Act includes the prohibition and punishment for stalking, substance attack, criminalizing incestuous conducts, protection order for victims and persons under threat of violence, and compensation for victims of violence. It provided for a register for convicted sexual offenders, which shall be maintained and accessible to the public.

Under the VAPP Act, rape, spousal battery, forceful ejection from home, forced financial dependence or economic abuse, harmful widowhood practices, female circumcision or genital mutilation, abandonment of children, harmful traditional practices, harmful substance attacks, such as acid baths, political violence, forced isolation and separation from family and friends, depriving persons of their liberty, incest, indecent exposure and violence by state actors (especially government security forces) among others are punishable offences.

Cultural factors that influences the perpetration of female domestic violence in Nigeria

Domestic violence has been shown to exist in various forms in most societies throughout the world. Indeed it is a global phenomenon. Nonetheless, acceptability of domestic violence 


\section{International Journal of Social Sciences and Management Review}

varies across cultures and societies due to the cultural perception of Domestic violence behaviour (Austin 2014)

Female domestic violence has been perceived by so many scholars to have a cultural origin. Variants (2017) commented that violence against women in our society is an insidious problem deeply rooted in our culture.

Violence against women in Nigeria is almost accepted as a fact of life in some cultures that perceive women as the property of their husbands. The Guardian Editorial of 10th February 2017 notes that "The prevention of domestic violence, first and foremost, requires challenging cultural and social norms that tolerate or excuse violence especially against women".

The Nigerian traditional cultural practices embrace the belief of superiority of males over females. The customs of marriage in this society give men proprietary rights over women and girls. It also encourages polygamy. Hence, the gender prejudice of preference of a male to the female child within the family structure pervades through various ethnic groups in Nigeria. This results in girls being given less educational privilege and other opportunities as compared to boys (Bakare, et al 2010)

Women have remained the chief sufferers of domestic violence in Nigeria, with perpetrators claiming to be acting in accordance with tradition. Akoh, 2016 as cited in Agbonkhese and Onuoha,(2017) commented that "When a woman is being married, a customary bride price is paid on her as a mark of respect to her and she, in return is expected to respect the husband. That is where tradition and culture involve such submissiveness but that should not in any way lead to abuse of privilege or wife battering many Africans practice it as a way of showing man's superiority over a woman".

Adeniyi in an exclusive interview with the Vanguard (January 20, 2018) affirms that the issue of the patriarchal society we live in is a serious problem, especially for the fact that the word "submission" has been bastardized. It is so bad that a lot of women do not know when they are even in an abusive relationship simply because of that word which has been abused.

While Musawa (2016) observes that Nigerian women's rights are often violated with impunity. In some communities, maltreatment of wives are often seen as justified, particularly in cases of actual or suspected infidelity on the part of the woman. There is sadly a deep cultural belief in Nigeria that it is socially acceptable to hit a woman, to discipline a spouse.

Studies have shown that there is a powerful social stigma around reporting violence, or, worse still, leaving your husband. Even among women, some survey found that $43 \%$ of women believe a husband is justified in beating his wife for a number of reasons, including going out without telling him or neglecting the children. This is related to the view about married women in Nigeria, by the Coordinator of Lagos State Domestic and Sexual Response Team (DSVRT) Titilola Adeniyi in the same interview with Vanguard weekend woman (the vanguard January 20, 2018) says that most women who came to the Lagos State Domestic and Sexual Violence Response Team (DSVRT) only want the violence to stop and will not 


\section{International Journal of Social Sciences and Management Review}

consider leaving their husbands. She is of the view that this has to do with cultural perception attached to a woman who walks out of a marriage. She is seen as a failure, she is regarded as promiscuous and most times, these are the ground on which these perpetrators denounce the woman. So they want to stay in the relationship to keep up appearance.

In many cases, there is no support from the family for a woman who leaves her husband. In the study made by Kohlman, Baig, DiRubbo, Placencia, Skale (2014) analysis shows that, the tendency for many cultures to value family privacy and prioritize the good of the family above that of the individual, referred to as "familism", contributes to the acceptance of abusive behaviour. The report further stated that familism can facilitate and perpetrate physical and emotional abuse by effectively preventing victims from seeking outside help or even perceiving their treatment as abusive.

\section{Mass Media Reportage of Domestic Violence against Women}

Newspaper and the broadcast media have been found to reflect and shape public opinion. The media can play a useful role in propagating information about domestic violence. It can be used to create awareness, convey education and serve as a deterrent to abusers. The media is able to feature as a key instrument in the prevention of violence because of its potential influence on shaping public understanding through news and information. Media report on current events provides a framework for the interpretation of such issues as domestic violence. Improving the way media report on the issue is one of the key ways they can be used to reduce Female Domestic violence in our society. (Carll, 2003 cited in Sutherland et al 2015).

Although news media audience are not simply passive recipients of information, yet what is selected to appear in the news and how these individuals and events are portrayed can have a profound influence on people's attitudes, beliefs, and behaviour (Flood and peace, 2009 cited in Sutherland et al 2015). This is to emphasize that, the way information is structured can increase public understanding of violence against women and girls and more importantly challenge its place in society.

In recent times there is a growing interest of research and literature on the influence of the media on the reduction of violence against women and girls. A report published by The Above Whispers Organization (2015) on the role of the media towards the reduction of violence against women in Nigeria reinforced the fact that the media are recognized all over the world as an agent of socialization, which moulds the morals, views and opinions of the society. They, therefore, need to step in and begin the education process towards preventing and ending violence and abuse in our society. Media educational campaign should target various age groups and other strata of the society and enable them to understand the root causes of violence in their communities. It should educate and involve communities to prevent such violence and to learn about where to access support if violence is experienced. The study goes further to suggested that this is the only way by which we can re-orientate ourselves about the desired attitudinal and cultural change to ensure that our society begins to understand the need to promote respectful relationships and gender equality. 


\section{International Journal of Social Sciences and Management Review}

Therefore, the media and civil society organizations must help in raising awareness about the criminal nature of domestic violence against women and the girl child, provide information about support services and protective laws, and encourage citizens to break the culture of silence by reporting cases of violations. (The Guardian Editorial, Feb.10, 2017).

Findings from numerous studies have demonstrated the ways in which media content reinforces violence against women and the girl child. These studies show that:

- Media content reproduces sexist stereotypes that associate male identity with violence, domination, independence, aggression and power, while women are depicted as emotional, vulnerable and sensitive, and dependent upon male actions (Elasmar, Hasegawa and Brain, 1999; McGhee and Frueh, 1980; Thompson and Zerbinos, 1995) Cited in Montiel, (2013).

- News reports of violence of gender tend to represent women as victims -associated with their lack of power- or, conversely, as those responsible for the violence of which they are victims. Usually, aggressors are not part of news reports (Diez, 2002; Montiel, 2007).

At this point, we would say that 'reducing women to sexual objects and making them available for consumption through communication and information technologies seems to be one of the most dramatic ways the media portrays female domestic violence. (Montiel, 2013).

\subsection{EMPIRICAL REVIEW}

Owolabi, Asuquo \& Agomoh, (2010) studied "Domestic violence and Nigeria women: A Review of the Present State". In the study, the authors dwelled more extensively on finding out factors that make men abuse their female partners. The work enumerated what they called an ecological model for understanding risk factors for violence as follows:

1) Individual Level; which has to do with genetic/ biological factors example developmental experiences, psychological problems like depression, propensity to anger, frustration, alcohol misuse and so on.

2) Relationship level: such as family, friends, peers, intimate partners may influence the risk of becoming perpetrator of violence. At this point childhood experiences of domestic violence or constant witness of domestic violence acts in childhood could be a risk factor.

3) Societal level: These include economic and social- politics, which maintains socioeconomic inequalities between people, socio-cultural norms such as male dominance over female, living in the urban household as compared to rural households as associated factors and so on.

The study recommended: To mitigate violence against women, there is a need for continuous public education with the aim of raising awareness among Nigerian populace. The use of television, radio and newspaper media can go a long way in improving the masses knowledge on gender based violence. It is also important to put more efforts into empowering women through equal educational and employment opportunities. 


\section{International Journal of Social Sciences and Management Review}

Abayomi \& Olabode (2013) carried out a study on "Domestic violence and Death: Women as Endangered Gender in Nigeria". The work looked into the tragic impact of domestic violence victimization. The report quoted the 2003 Massachusetts Domestic Violence Homicide Report (MDVHR), where the authors wrote: 'the human toll from domestic violence is grossly underestimated ... Domestic violence homicides represent just the tip of the iceberg regarding mortality and morbidity resulting from domestic violence. Suicides that can be attributed to domestic violence deaths that result from life-long battering also need to be examined. Within the category of homicide, alone, it is difficult to claim with any certainty that we were able to identify all domestic violence homicide incidents.

The study highlighted some of the gory reports of cruelty against women in Nigeria which shows that the women are indeed the endangered gender specie in Nigeria as violence against women is concerned.

The paper recommended among other things that the prevalent problem of stereotype and patriarchy must be urgently addressed. The Nigerian society must undergo re-construction and re-engineering in order to confront stereotypes and patriarchy that has put the womenfolk on the danger list. This could be done through awareness creation, education and consultation with stakeholders in the society such as traditional leaders who are custodians of culture, leaders of religious bodies, community associations and the media. This will help in changing how society views and understands power relations between men and women.

Linos, Slopen, Subramanian, Berkman \& Kawachi (2013) carried out a study on The Influence of Community Social Norms on Spousal violence: a population-based multilevel study of Nigeria Women.

The study sought to know whether social norms toward spousal violence in Nigeria, at the state level, are associated with a woman's exposure to physical and sexual violence perpetrated by their husbands. The study questioned whether social norms justifying female domestic violence or intimate partner violence (IPV) were positively associated with a woman's risk of becoming a victim of such violence.

The study made use of Social norm theories which may be used to explain behavioural interventions to explain the prevalence of "negative" behaviours, such as heavy drinking or smoking. The study found that social norms can constrain individual behaviours, through social enforcement or the sanctioning of certain behaviours based on implied consequences of not complying. The study predicted higher rates of spousal violence in communities with more accepting norms around such violence.

At the individual level, the study showed a significant positive association between a women's accepting beliefs toward spousal violence and their own report of sexual and physical violence victimization. At the contextual level, the study also found that women living in states with Sharia law were less likely to report spousal violence. The study recommended that solutions should be expanded to include the community at large.

Syed \&Syed carried out a study on "News Coverage of Physical Violence against Women: Where Do we Position". The study was based in Pakistan and was published on January 


\section{International Journal of Social Sciences and Management Review}

2016. The researchers choose content analysis as a research design for the study. Two newspapers were chosen namely the Daily Jang and Daily Khabrain from 1st October 2012 to March 30, 2013. The main purpose of this study was to investigate how much news is given by the Urdu dailies as related to the issue.

In comparing the proportion of the two newspapers on the issue, the researcher found out that Daily Khabrain was greater in proportion with 74.43 per cent space coverage of the issue than Daily Jang which had 25.57 per cent space coverage. The study found that, although media is playing its role in reporting news on physical violence against women but need improvement for more effective work.

Ebenezer Owusu- Addo, Sally B Owusu- Addo, Ernestina F. Antoh, Yaw A. Sarpong, Kwaku Obeng-Okrah and Grace Annan studied "Ghanaian Media Coverage of Violence Against Women and Girls: Implication for Health Promotion". The study used frame analysis which involves both quantitative content analysis and qualitative analysis as the methodological framework in examining how violence against women and girls (VAWG) in Ghana is represented by the media. Qualitative content analysis approach to frame analysis was performed on 48 news articles which constituted the unit of analysis. The researchers chose five media outlet to code from January 2014 to December 2014. The media outlets chosen were: The Ghanaian Times, Daily Graphic and Daily Guide for newspapers and FM stations were Peace FM and Joy FM. The main purpose of the study was to examine news coverage of VAWG in Ghana and the implication of this for health promotion.

The findings indicated that media framing of VAWG was episodic in nature as the acts of violence perpetrated against women and girls were presented as individual cases without reference to the wide social contexts within which they occurred. Similarly, the victimblaming language was largely used in news articles. In framing VAWG as an individual incident and women as helpless victims, the media fail to shape society's perception of VAWG as a social and public health issue. Furthermore, the study suggested that, for media in Ghana to contribute to the prevention of VAWG, there is the need for news coverage to focus on the social construction of the issue and also raise awareness about support services available to victims.

\subsection{THEORETICAL FRAMEWORK}

This work is based on the agenda setting theory of the mass media. Agenda setting theory is premised on the idea that what the public thinks about is set by the media. The agenda-setting theory was first introduced by Dr Maxwell McCombs and Dr Donald Shaw in 1972. This theory states that the mass media news plays an integral part in the shaping of political realities. The amount of time spent on an issue and the information relayed in a news story, along with the story's position, determines how much a reader learns and the amount of importance placed on the issue. The agenda setting theory of McCombs and Shaw states that when the media reflect on the views of people in any issue, they are also shaping and determining the issues of importance.

When analysing the agenda setting, there are two basic assumptions to be considered: 


\section{International Journal of Social Sciences and Management Review}

1. Media and the press filter and shape reality rather than reflect it.

2. When the media focuses on just a few issues and subjects, the public tends to perceive those issues as more important.

The question is, what issues are important to people? Why are these issues of importance? So far we can see that Media coverage not only directs what we think but also shapes how we think. This influence provides media with a powerful tool to influence the government and the way people view it.

Therefore, when the media starts to focus attention on issues of domestic violence in our society, telling the devastating nature of it and not giving a sensational approach but a holistic, informational and educational approach; then the same will be the way the society will see it and with time will change their attitude towards violence against the female fold in this part of the world.

\subsection{METHODOLOGY}

This study was designed using the content analysis method. The manifest content of the selected dailies was evaluated to ascertain the pattern and degree of coverage given to domestic violence involving women. The contents were also analyzed to establish the direction of the Nigerian press with regard to the research topic. The select newspapers were The Sun Newspapers, The Guardian Newspapers and The Punch Newspapers for a period of one year (January 1 to December 31, 2017). Justification for the selection of these newspapers was the fact that they are national newspapers and their reach is nationwide. They enjoyed wide readership all over the country at the time of this study. They, therefore, can be used to represent other national dailies in the country. Furthermore, the selected newspapers are not for specialized readers but rather target the general public. Since the papers are dailies, including their weekend editions. The total number of days in a year multiplied by three; 365 days $\times 3=1,095$. The total population of the study, in this case, is 1,095 editions of the newspaper. From the population, a sample of 72 (24 x3) was drawn. Hero Stample (1957) cited in Obayi, et al (2015:45) argued that a selection of 14 editions of the newspaper, depending on the study is enough to study one year. The researchers then adopted the composite month sampling technique for this study.

In drawing a composite month sampling technique, the first route is to draw a composite month sample schedule for the selection. By packing all the days of the month in one basket, the researcher randomly picked two days out of every month for the study. This was repeated for all the months of the year understudy for each of the selected newspapers.

The unit of analysis examined in this study was the straight news, feature news and editorial news stories on domestic violence involving women in Nigeria while the content categories include, frequency of coverage, prominence, the direction of coverage and language used by newspapers in reporting news on female domestic violence.

Data were analysed using simple percentages, while Chi-square Goodness of fit was used to test for the hypothesis. This is because according to Obayi et al (2016) Chi-square goodness of fit is more suitable for a linear hypothesis to see how they fit. 


\section{International Journal of Social Sciences and Management Review}

\subsection{DISCUSSION OF FINDINGS}

On the level of frequency of the coverage of different types of domestic violence against women, more coverage is given to intimate partner homicide than other forms of domestic violence against women. Physical and emotional abuse of women was next in number after intimate partner homicide. Sexual abuses of women did not appear much in the coded publication may be because these cases are rarely reported in our society. Other forms of violence as coded in the study are stories that did not state any particular case, mostly found in feature and editorial news items.

For the direction of news coverage on domestic violence against women in Nigeria, out of the 31 coded news stories on domestic violence against women, 20 stories were coded as being favourable. 8 stories were coded as unfavourable and 3storiewere coded as neutral. This shows that news stories on female domestic violence enjoy favourable coverage than unfavourable and neutral news on domestic violence against women in Nigeria.

To determine the level of prominence accorded to female domestic violence in Nigerian newspapers, the study considered the placement of stories in the selected edition of newspapers. Findings show that prominence level accorded to female domestic violence stories in Nigerian newspapers is low as the majority of the stories is found inside the pages of the sampled publication. The table shows that out of 31 coded news stories, 27 stories were placed inside the pages representing $87.1 \%$ while two stories were found on both the front page and center spread and none at all were found at the back page. Since the front and the back page are the attraction of the readers, and very few stories of female domestic violence are found there, it then gives rise to the conclusion that Nigerian newspapers do not accord much prominence to female domestic violence stories.

To ascertain the styles and language used in framing female domestic violence stories, the content of the news stories were examined and interpreted to find the tone used in publishing news stories on female domestic violence. The tone was categorized into the following: Aggression, persuasive, and calm. Stories that depict aggression are those that show the level of hostility as demonstrated by the action or where the writer shows how grievous the act was.

This is expressed in the following ways from the sampled publication.

In the story captioned "Husband cuts wife throat, claims she committed suicide, police tells court"

"My team visited the scene of the crime and observed that the throat of the deceased was ruthlessly slit, as her blood painted the entire floor of their three-bedroom flat bungalow apartment". (The Sun January 18, 2017).

"The command's spokesperson added that the command would bring to book all perpetrators of heinous acts in the state" The report added this also; 


\section{International Journal of Social Sciences and Management Review}

"The act shocked and threw the community into serious mourning because it was its first time of witnessing such an act". (The Guardian, September 12, 2017).

Another story reads; "What happened to my sister is a very painful thing. She was the breadwinner of our family and only a few people would understand how we feel now". (The Sun, March 10, 2017).

Persuasive news stories are where the writer presents his story with a strong argument and reasons for or against the act of female domestic violence.

Examples are shown thus:

"Highlight of warning signs of abusive relationships"... "If your partner blames you for the abuse"

"The longer you stay in an abusive relationship, the greater the physical and emotional toill". (The Sun, December 17, 2017).

\section{Another story reads:}

News stories coded as calm. Calm language as coded in the study is those news stories that neither showed anger non-hostility towards the action. In other words, they show no serious harm done to the perpetrators.

\section{An example is as follows.}

"He observed that most times the women withdrew their charges before hearing were started because family members always reminded them that the men were their lawful husbands and fathers of their children"(Daily Sun, April 13 2017).

Data shows that out of 31 stories coded, 16 stories were coded as aggressive and 10 stories as persuasive while 5 stories were coded as calm. Therefore we say that female domestic violence news was more presented in aggressive tones than other tones.

\section{Test of Hypothesis:}

In appraising the result drawn from the analysis of this study, we used chi-square goodness of fit to determine the results.

"There is a low level of prominence accorded to the coverage of female domestic violence news by Nigerian newspapers".

Since prominence is measured by placement of news stories in the newspaper, data shows that most domestic violence news stories against women were buried in the inside pages of the newspapers. Out of a total of 31 coded stories on domestic violence against women twenty-seven (27) were found inside pages while only two were found in front page and none was found on the back page. 


\section{International Journal of Social Sciences and Management Review}

Volume: 03, Issue: 04 "July - August 2020"

ISSN 2582-0176

\begin{tabular}{|l|l|l|l|l|l|}
\hline Newspapers & Front page & Inside page & Center spread & Back page & Total \\
\hline The Sun & $1(8.3 \%)$ & $10(83.3 \%)$ & $2(8.3 \%)$ & 0 & $12(38 \%)$ \\
\hline The Guardian & 0 & $8(100 \%)$ & 1 & 0 & $8(25.8 \%)$ \\
\hline The Punch & $1(9.1 \%)$ & $9(81.8 \%)$ & $1(9.1 \%)$ & 0 & $11(35.5 \%)$ \\
\hline Total & $2(6.5 \%)$ & $27(87.1 \%)$ & $3(6.5 \%)$ & 0 & $31(100 \%)$ \\
\hline
\end{tabular}

Using Chi-square Goodness of Fit to calculate the hypothesis

\begin{tabular}{|l|l|l|l|l|l|}
\hline & $\begin{array}{l}\text { Observed } \\
\text { Frequency }\end{array}$ & $\begin{array}{l}\text { Expected } \\
\text { Frequency } \\
- \text { Exp) }\end{array}$ & $\begin{array}{l}\text { Residual (Obs } \\
(\text { Obs } \\
\text { Exp })^{2}\end{array}$ & $\begin{array}{l}\text { Component } \\
(\text { Obs } \\
\text { Exp })^{2} / \mathrm{exp}\end{array}$ \\
\hline Front page & 2 & 10.3 & -8.3 & 68.89 & 6.69 \\
\hline Inside page & 27 & 10.3 & 16.7 & 278.89 & 27.1 \\
\hline $\begin{array}{l}\text { Centre } \\
\text { spread }\end{array}$ & 2 & 10.3 & -8.3 & 68.89 & 6.69 \\
\hline Total & 31 & & & & $\mathrm{X}^{2}=40.48$ \\
\hline
\end{tabular}

Here the calculated result is 40.48 . However, to take a stand on the Hypothesis, the result must be cross-checked on a chi-square table. Obayi, et al (2016) stated that in chi-square, two things are necessary "the probability level of 0.05 " and "the degree of freedom".

Degree of freedom in chi-square goodness of fit is calculated as K -1 where K represents the different level of data set, therefore;

$$
\begin{array}{ll}
\therefore \quad \mathrm{df}=\mathrm{K}-1 \\
& =3-1=2
\end{array}
$$

If cross-check at 0.05 table value equals to 5,991. The rule is that, if the calculated value equals or exceeds table value, the alternate hypothesis is accepted and the null hypothesis rejected. Therefore, the calculated value here is 40.48 while table value is 5.991. It then follows that this study accepts the claim that there is a low level of prominence accorded to the coverage of domestic violence against women in Nigerian Newspaper.

This then follows that the Nigerian newspapers do not accord much prominence to domestic violent news against women or that the media in Nigeria do not attach much importance to news stories of domestic violence involving women. Based on these findings, we can, therefore, infer that the media have failed to use their agenda-setting power to project domestic violence against women as a broader social, psychological and health problem ravaging our society. 


\section{International Journal of Social Sciences and Management Review}

This study finding is largely similar to the work of Hassan Raza et al 2016. (www.iiste.org) (Pakistan) in their work titled "news coverage of physical violence against women: where do we position" and that of Owusu-Addoet al 2018 (https://doi.org/10.1186/s12905-018-0621-1) (Ghana) with the title "Ghanaian media coverage of violence against women and girls: implications for health promotion" which confirms that the media fails to adequately inform and educate the public about issues on domestic violence.

\subsection{SUMMARY}

This research work probes the coverage of female domestic news in Nigerian newspapers. The researcher tried to examine the extent and manner of coverage of stories relating to female domestic violence in Nigeria.

The work is a content analysis where three national newspapers are examined namely; The Sun, The Guardian and The Punch newspapers. The researcher content analyzed these papers for the period of one year (2017). Code sheet was used in coding the data in terms of data presentation and analysis. The unit of analysis was the straight News stories, editorial and feature news stories on domestic violence. The content categories were based on frequency, direction, language, and how placement or prominence of news stories. Tables were used to present the data in its simple percentage form and simple mathematical tools such as bar chart and pie chart were also used to present the data.

\section{The following are therefore the summary of the findings:}

From the findings it is deduced that most of the media coverage of domestic violence stories are on intimate partner homicide. News stories on sexual assault and rape are rarely reported. Majority of the stories on domestic violence against women in the samples newspaper were placed on the inside pages which means that the level of prominence accorded to female domestic violence stories are low.

While we see the majority of news stories under favourable tone, a good number of a report on domestic violence, are unfavourable because reporters depend highly on police account of what happened and showed reasons given by the perpetrators for blaming their victims for what happened to them. The length of most stories on against women depicts that most of these stories lack depth investigation of what happened because most of this stories are not given in-depth analysis that was why few stories were coded for feature stories.

In conclusion, it seems that women are discriminated against in every sphere of life. The high prevalence and intensity of violence against the female folk most times arise from local customs, traditional beliefs and value systems.

Here comes then the responsibility for the media. The media is recognized all over the world as an agent of socialization, which moulds the morals views and opinions of society. It, therefore, needs to step in and begin the education process towards preventing and ending violence and abuse in our society. The education should target various age groups and other strata of the society and enable them to understand the root causes of violence in their 


\section{International Journal of Social Sciences and Management Review}

Volume: 03, Issue: 04 "July - August 2020"

ISSN 2582-0176

communities, to educate and involve communities to prevent such violence and to learn about where to access support when the need arises.

This study, therefore, recommends that there is need for the media to channel their news report of domestic violence against women towards educating the mass and bringing this discourse into the political agenda. There is a need for a more representative way of reporting domestic violence against women as this can be part of the solution to eradicate domestic violence in our society. Also, Newspapers should give a more in-depth analysis of news bordering on domestic violence against women and not to see it as less important news. Again there is need for the media to accord more prominence to news stories on domestic violence against women because this will go a long way to set the agenda to the crusade of eradicating this ugly trend of domestic violence in our society.

\section{REFERENCES}

Abayomi A. A. \& Olabode, K. T. (2013) Domestic Violence \& Death: Women as Endangered Gender in Nigeria. American Journal of Sociological Research 2013, 3 (3):53- 60 .

Agbonkhese \& Onuha (2017): Does Nigeria Culture Permit Domestic Violence? The Vanguard Newspaper August $24^{\text {th }} 2017$.

Asemah, E., Nwammuo A \& Nkwam-Uwaoma A. (2017): Theories and Models of Communication. Jos: University Press.

Bakare M. O, Asuquo M. D. Agomoh A. O. (2010) Domestic Violence and Nigeria Women. A Review of the Present State. Available at www.researchquate.net/publication/259487750-

Davoren H. (2015): Domestic Violence and Media-Maintaining the Veil of Silence and Secrecy Retrieved September 302018 from www.abc,net.au/news/2015-05$\underline{08 / \text { davoren }}$

Ebele, N (2017) Is Domestic Violence a norm in Nigeria? The Guardian $4^{\text {th }}$ October, 2017

Fayombo G. A. (2000), Women Abuse: Psycho-Physical Assault, Ethnic and Differing Marital Experiences as Precursors of Women Abuse in Nigeria. Nigeria School of Health Journal Vol. 12, No. 1 \& 2,

Fagboyo M. (2016) The role of the media towards reduction of Violence Against woman in Nigeria: Using the violence against persons prohibition (VAPP) Act 2015. Retrieved 15 September 2018 from www.abovewhispers.com.

Jaiyesim R.O.A. (2001) - Protection Against Domestic Violence Law 2007 - (Compiled by the Clerk of the House of Assembly Lagos State House of Assembly - (18 ${ }^{\text {th }}$ May 2007)

Kohlman S. et al (2014): Contribution of Media to the Normalization and Perpetuation of Domestic Violence. Journal of Psychiatry and Behavioural Sciences 


\section{International Journal of Social Sciences and Management Review}

Volume: 03, Issue: 04 "July - August 2020"

ISSN 2582-0176

Linos, N. et al (2013): Influence of Community Social norms on Spousal Violence: A Population-based Multilevel Study of Nigeria Women. American Journal of Public Health 103 (i): 148 - 155.

Montiel A (2018): Violence Against Women and Media: Advancements and Challenges of a Research and Political Agenda. Retrieved September 112018 from www.//nomanstats.wordpress.com/13/06/20/

Montiel A. (2013) Violence Against Women and Media: Advancements and Challenges of a Research and Political Agenda: Retrieved October 29 from https://womanstats.wordpress.com/13/06/20/

Musawa H. (2016) Surging Domestic Violence Rate Against Woman in Nigeria: Retrieved September 122018 from www.nationonline-net/Surging-domestic-violence-Rate$\underline{\text { Women }}$

Obayi P.M, Anorue L.I, Onyebuchi C.A (2016) Demystifying Content and Data Analysis in Social Science Research. Enugu: Degreat Publishers.

Olowoorejo M (2017) Domestic Violence: 88 Percent of Cases Lack Evidence - Lagos Government Vanguard: May, 122017.

Oluremi F.D (2015) Domestic Violence against Woman in Nigeria. Retrieved September 18, 2018 www.idpulication.org/wp-content/up-content/upload/2014/12/DMESTIC.

From

Onyemelukwe C. (2017) How well does the Law protect Women at home? An Analysis of Nigeria's Domestic Violence Legislation. Centre for Health Ethics, Law and Development. Lagos: Emerald Publishing Ltd: Available at https://www.emeraldinsight.com/doi/full/10.108/IJLMA-05-2017-0111.

Raza S. \& Hussain S. (2016): News Coverage of Physical Violence against Women: Where do we Position? Journal of Culture Society and Development International PeerReviewed Journal Vol. 19

Sutherland G. et al (2015): Media Representation of Violence against Women and their Children: State of Knowledge paper: Australia's National Research Organization for Women's Safety (ANORM) Retrieved September 182018 from https://www.ourwatch.orian/get.media/389a

TCR Staff (2017): Poor Domestic Violence Coverage May 'Perpetuate' Abuse. Retrieved August 18, 2018 from https://thecrimreport.org/2017/07/03

The Guardian Editorial Board (2017) All against Domestic Violence. The Guardian Newspaper. $10^{\text {th }}$ February 2017

The Punch Editorial Board (2017) 2017 Year of Deadly Domestic Violence Cases. The Punch Newspaper $31^{\text {st }}$ December 2017 


\section{International Journal of Social Sciences and Management Review}

Udobang W. (2018): We are brought up to think suffering this Violence is Ok: Domestic Abuse in Nigeria. The Guardian Jan., 5, 2018.

Usigbe L. (2018): Nigeria women say "no" to gender-based violence: United Nations Africa Review.

Retrieved October 212018 from https://www.un.org/africanrenewal/nigerian-woman$\underline{\text { say-no }}$

Violence Against Persons Prohibited Act. (2015). A bill for An Act to eliminate violence in private and public life, prohibit all forms of violence.www.naptp.gov.ng/wp-content/

World Health Organization (2017) World Report on Violence and Health: Violence against women.

Retrieved October 20, 2018 from database.unwoman.org/-/media/files/unwoman/vaw/ 